\title{
A culturally and sex specific behavioural intervention reduced sexually transmitted diseases in minority women
}

Shain RN, Piper JM, Newton ER, et al. A randomized, controlled trial of a behavioral intervention to prevent sexually transmitted disease among minority women. N Engl J Med 1999 Jan 14;340:93-100.

\section{Question}

Can a culturally and sex specific small group, cognitive behavioural intervention prevent sexually transmitted diseases (STDs) in high risk African-American and Mexican-American women?

\section{Design}

Randomised, unblinded, controlled trial with follow up at 6 and 12 months.

\section{Setting}

Public health clinics in San Antonio, Texas, USA.

\section{Patients}

617 English speaking, Mexican-American and AfricanAmerican women, who had a non-viral STD (chlamydial infection, gonorrhoea, syphilis, or trichomonal infection). 6 and 12 month follow up rates were $82 \%$ and $89 \%$, respectively.

\section{Intervention}

After stratification by race and ethnicity, 313 women were allocated to the behavioural intervention, which consisted of 3 weekly small group sessions, each lasting 3-4 hours. Groups comprised 5-6 women and a trained woman facilitator, all of whom were of the same race or ethnicity. 1 session addressed the recognition of risk (eg, minorities are disproportionately affected by STDs and awareness of personal risk), the second addressed commitment to change (eg, information on prevention of STDs, early treatment and compliance, and use and application of condoms), and the third addressed acquisition of skills (eg, communicating and negotiating with partner about sex and contraception and discussion of triggers to unsafe sex). Learning was personalised, and participants were involved in open discussions, games, watching videotapes, behaviour modelling, and role play. 304 women were allocated to the control group and received approximately 15 minutes of standard individualised counselling by nurse clinicians according to guidelines from the US Centers for Disease Control and Prevention.

\section{Main outcome measures}

Subsequent infection with Chlamydia trachomatis or Neisseria gonorrhoeae, assessed by testing of endocervical samples with DNA probes.

\section{Main results}

Analysis was by intention to treat. At 12 months, fewer women in the intervention group had $\geq 1$ episode of infection (an occurrence of gonorrhoea, chlamydial infection, or both) (table). Multiple logistic regression analysis (with covariates and controlling for age and number of sex partners) showed that women in the intervention group were less likely to have an STD at 6 months (adjusted odds ratio $0.58,95 \%$ CI 0.34 to 0.99 ) or 12 months (adjusted odds ratio 0.52, CI 0.34 to 0.81 ).

\section{Conclusion}

A culturally and sex specific behavioural intervention reduced subsequent chlamydial infection and gonorrhoea in high risk African-American and Mexican-American women.

Behavioural intervention v control for number of women with $\geqslant 1$ episode of gonorrhoea or chlamydial infection at 12 months*

\begin{tabular}{llll}
\hline $\begin{array}{l}\text { Behavioural } \\
\text { intervention }\end{array}$ & Control & RRR (95\% CI) & NNT (CI) \\
\hline $16.8 \%$ & $26.9 \%$ & $37.4 \%(13.5$ to 54.8$)$ & $10(6$ to 32$)$ \\
\hline
\end{tabular}

*Abbreviations defined in glossary; RRR, CI, and NNT calculated from data in article.

Source of funding: National Institute of Allergy and Infectious Diseases.

For correspondence: $\operatorname{Dr} R \mathrm{~N}$ Shain, Department of Obstetrics and Gynecology, University of Texas Fealth Science Center at San Antonio, 7703 Floyd Curl Drive, San Antomio, TX 78284-7836, USA. Fax +12105674963.

\section{Commentary}

Although studies have shown that interventions to prevent STDs can increase self reported condom use, ${ }^{1}$ this study by Shain et al is one of the few to examine the effect of an intervention on clinical disease. The authors suggest that behaviour changes that lead to prevention of non-viral STDs may be considered a proxy for changes that prevent transmission of HIV; however, they chose common STDs as their outcome measures because of the low prevalence of HIV in this particular population.

All of the women in the study received financial incentives for their attendance, which may account for the high rate of continued participation $(75 \%$ of the women attended all 3 sessions and 89\% were available for the follow up at 12 months). The control group received 15 minutes of individualised STD counselling at the first visit, which may have influ- enced their reinfection rate.

The design of the intervention was based on the findings of 25 focus group interviews, 102 indepth interviews, and observations in low income, inner city communities. As a result, the intervention incorporated cultural and ethnographic information highly specific to the target population of Mexican-American and African-American women. This enhanced the effectiveness of the intervention, but limits generalisability to other populations. However, nurses contemplating risk reduction strategies for other high risk and minority groups will be able to use the principles of the participatory action style design.

The results are relevant to nurses working with high risk women or minority groups. This could include nurses practising in women's resource centres, public health units, women's shelters, community health centres, HIV/AIDS education centres, needle exchanges, correctional centres, street nurses, or school health nurses. The essence of the research creates a snowball effect, prompting further research to answer questions such as "what cultural and ethnographic factors should be incorporated into an intervention for prostitutes in urban centres?" The results also allude to the importance of communication with and among participants and highlights the need for nurses to be open minded and non-judgmental when working with these populations.

Jo Wood, RN, MN

Formerly Safe Works Needle Exchange Calgary, Alberta, Canada

1 Kalichman SC, Carey MP, Johnson BT. Prevention of sexually transmitted HIV infection: a tion of sexually transmitted HIV infection: a
meta-analytic review of the behavioural outmeta-analytic review of the behavioural out-
come literature. Ann Behav Med 1996;18:6-15. 